\title{
Histopathological analysis of appendectomy specimens in Calabar, south -southern Nigeria
}

\author{
A J Omotoso ${ }^{1}$, M A Nnoli ${ }^{1}$, IE Bassey ${ }^{1}$, A O Akintomide ${ }^{2}$, O E Ngim ${ }^{3,}$ \\ I A Ekanem ${ }^{1}$ \\ ${ }^{I}$ Department of Pathology, University of Calabar \\ ${ }^{2}$ Department of Radiology, University of Calabar Teaching Hospital Calabar \\ ${ }^{3}$ Department of Surgery, University of calabar
}

\begin{abstract}
Background: Appendectomy is one of the commonest surgical intervention worldwide with a very high incidence in Nigeria. The various histologic patterns of these lesions are diverse with little information about this in this part of the country.
\end{abstract}

Aim: To analyse various histologic pattern of appendectomy specimens received in University of Calabar teaching Hospital.

Materials and Methods: This is an eleven year (1999-2009) retrospective study involving review of the histologic records of all patients with gastrointestinal lesions received in the Department of Pathology, UCTH. The patients' biodata and histologic diagnosis were retrieved. Analysis was done using simple statistical operation.

Results: We found that $46.2 \%$ of all the gastrointestinal lesions were appendectomy specimens: Out of these, $44.7 \%$ were acute appendicitis with or without complications while $7.8 \%$ belong with appendix specimens that either had no pathology or were autolysed and the remaining $48 \%$ show either reactive lymphoid hyperplasia or appendix with chronic inflammatory response. There was no neoplasia or carcinoid found among the lesions. Furthermore, we found a male to female incidence of 1: 1.45 for the acute appendicitis, with the mean age being 35 and 31 years old for males and females. In our series, the youngest patient was 6months old while the oldest was 73.

Conclusion: Appendectomy specimen is the commonest gastrointestinal lesion received in Histopathology Department of UCTH, Calabar. Appendicitis remains commoner among the females than the males. Significant number of these patients had lymphoid hyperplasia.

\section{Introduction}

Appendicitis is an inflammation of the appendix and a common cause of acute abdomen. It occurs at any age but is commonest in the younger age group. The classic history is the onset of central abdominal pain.

Often associated with vomiting which localizes to the right iliac fossa. Examination may show a distressed patient who is febrile, has a coated tongue with foetor oris and has abdominal tenderness to palpation which is maximal in the right iliac fossa. This is usually associated with guarding and rebound tenderness may be present. A full blood count may show a raised white cell count with a neutrophilia.

Appendicitis is the leading cause of surgical emergency admission in most hospital in Nigeria. It accounts for about $15-40 \%$ of all emergency surgery done in most centers in the country. ${ }^{1}$ All age groups can develop the disease including the fetus in utero, but the incidence is higher in the second and third decade of life. Majority of patients in Nigeria present late with complicated disease ${ }^{1}$. Acute abdominal pain is the most common condition necessitating surgical admission to a pediatric hospital. The vast majority of cases are due to either appendicitis or acute non-specific abdominal pain. ${ }^{1}$

Surgical removal of vermiform appendix (appendectomy) is the treatment of choice for appendicitis. However, patients must be adequately resuscitated before the procedure. Prognosis is excellent. High morbidities and occasional mortalities seen are usually due to late presentation and delay in treatments. Fear of surgery and cost of treatment are the main reason for late presentation. Elechi EN showed a mortality rate of 3\% in appendectomy specimens reported in Port Harcourt, complicated appendicitis in this review was largely due to pre-admission delays ${ }^{2}$

It is generally reported to be more common in males ${ }^{3,4,5}$ although Mangete from Port-Harcourt and Archibong in Calabar Nigeria, found a significantly higher incidence in females. ${ }^{6,7}$.

The investigation of the acute abdomen especially in children has evolved over the years, Ultrasound and Computerised Tomography (CT) scans of the abdomen have increasingly become helpful in reaching a 
diagnosis, placing radiologists at the forefront of the evaluation and diagnosis of acute right lower quadrant abdominal problems. ${ }^{8}$ Although some worry on the widespread use of CT in children has been expressed concerning radiation. The reported sensitivity of ultrasound varies between 87 and $95 \%$ vs $95-97 \%$ for helical CT while the specificity ranges between 85 and $98 \%$ for ultrasound and 94 and $97 \%$ for helical CT. ${ }^{1,8}$

Taurous et $\mathrm{al}^{9}$ concluded that Ultrasonography is still a useful tool in the diagnosis of acute appendicitis in spite of sophisticated investigations like CT abdomen and laparoscopy; thus, reducing the cost of treatment and preventing negative laparotomies.

Ultrasound criteria for the diagnosis of acute appendicitis include the identification of tubular, non compressive, aperistaltic bowel which demonstrates a connection with caecum and blind terminal. Others include measurement of the antero-posterior diameter, mural thickness, and width of peri-appendicular fat tissue. These are highly significant ultrasound criteria in the evaluation of the appendix inflammation level. ${ }^{10}$

$\mathrm{CT}$ is a complementary tool ${ }^{1}$ but in the developing nations like Nigeria these imaging tools may not be accessible or affordable by the patient.

\section{Methodology}

Archives of the UCTH Histopathology for the Alimentary canal lesions were extracted and appendectomy lesions sieved from them; this spanned the 11-year period from 1999-2009. The information extracted included patients' Histology/lab numbers, age, sex, and histopathologic diagnosis. The data obtained were then analyzed by simple statistical method.

EXCLUSION CRITERIA: Patients with inadequate demographic information were excluded from the study.

\section{Result}

A total of 712 gastrointestinal specimens were received in the reception of the pathology department of UCTH, Calabar during the study period, 329 of the specimens were appendectomy lesion. This makes appendectomy specimen the leading surgical material received with $46.2 \%$. An average of 30 appendectomy specimens was received annually.

Table 1 Annual Incidence of Appendectomy and gastrointestinal specimens

\begin{tabular}{|l|l|l|l|l|}
\hline S/no & Year & $\begin{array}{l}\text { Total no of Appendix } \\
\text { specimen }\end{array}$ & $\begin{array}{l}\text { Total no of Alimentary } \\
\text { tract specimen. }\end{array}$ & Percentage \% \\
\hline 1 & 1999 & 12 & 30 & 40 \\
\hline 2 & 2000 & 28 & 56 & 50 \\
\hline 3 & 2001 & 23 & 46 & 50 \\
\hline 4 & 2002 & 10 & 40 & 25 \\
\hline 5 & 2003 & 31 & 54 & 57.41 \\
\hline 6 & 2004 & 23 & 58 & 39.66 \\
\hline 7 & 2005 & 15 & 41 & 36.59 \\
\hline 8 & 2006 & 34 & 63 & 53.97 \\
\hline 9 & 2007 & 55 & 105 & 52.38 \\
\hline 10 & 2008 & 49 & 100 & 49 \\
\hline 11 & 2009 & 51 & 119 & 42.86 \\
\hline & TOTAL & $\mathbf{3 2 9}$ & $\mathbf{7 1 2}$ & \\
\hline
\end{tabular}

There was female preponderance in the appendectomy specimens with male to female ratio of 1:1.2. Acute appendicitis with or without complication is seen more among the male folds so also are chronic inflammatory lesions.

Four cases of schistosoma appendicitis were seen during the study period and these cases were only seen in male while eight cases of eosinophilic appendicitis were seen.

There was no case of malignancy or carcinoid tumour during the study period while 21 cases showed no pathology. Reactive lymphoid hyperplasia was seen in 138 cases which is about $42 \%$ of the total appendectomy lesions. 
Table 2 Pathological Changes in Appendectomy Specimens with gender distribution

\begin{tabular}{|l|l|l|l|}
\hline & & & \\
\hline A) Inflammation & Male & Females & Total \\
\hline 1)Acute & & & \\
\hline 1.1 Acute appendicitis & 69 & 46 & 115 \\
\hline $\begin{array}{l}1.2 \\
\text { suppurative+peritonitis/gangrene }\end{array}$ & 18 & 14 & 32 \\
\hline & & & \\
\hline 2)Chronic & & & \\
\hline 2.1 chronic non specific & 5 & 3 & 8 \\
\hline 2.2 parasitic & 4 & 0 & 4 \\
\hline 2.3Eosinophilic & 3 & 5 & 8 \\
\hline & & & \\
\hline 3)Others & & & \\
\hline 3.1)Neoplasia & Nil & Nil & \\
\hline 3.2)Appendicial Carcinoid & Nil & Nil & \\
\hline 3.3)No pathological changes & 4 & 17 & 21 \\
\hline 3.4) Lymphoid Hyperplasia & 45 & 93 & 138 \\
\hline 3.5) autolysed specimen & 1 & 2 & 3 \\
\hline Total & $\mathbf{1 4 9}$ & $\mathbf{1 8 0}$ & $\mathbf{3 2 9}$ \\
\hline & & & \\
\hline
\end{tabular}

Acute appendicitis was seen more in their thirties while other lesions are seen at the lower age group. The average age of presentation for appendectomy in this study was about 28.5 years.

The 21-30 age group had the highest frequency followed by the $11-20$ age group at $32.2 \%$ and $23.1 \%$ of the total number of specimens respectively. The $71-80$ age group had the least frequency at $0.34 \%$.

Table 3: Average Age of Presentation

\begin{tabular}{|l|l|l|}
\hline Pathology & Sex & Average Age \\
\hline Acute Inflammatory & Male & 35 \\
\hline & Female & 31 \\
\hline Chronic Inflammatory & Male & \\
\hline & Female & 27 \\
\hline & & 24 \\
\hline Others & Male & 19 \\
\hline & Female & 35 \\
\hline
\end{tabular}

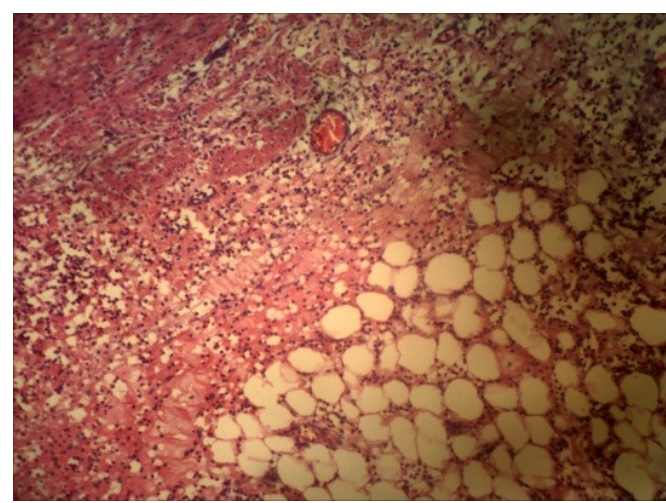

Figure I: Histologic section of acute suppurative appendicitis with peritonitis 
Section shows a tissue with oedematous stroma, congested blood vessels and infiltration of acute inflammatory cells into the stroma. This is a section from ruptured appendix with infiltration of the inflammatory cells into the mesoappendix. The patient often present with fever, the organ is red, oedematous, and tender with loss of its function. Such conditions may be complicated with peritonitis and septicemia.

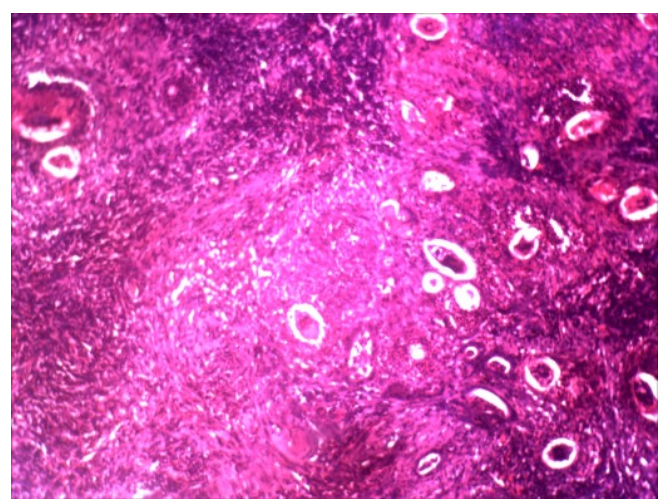

Figure II: Section of schistoma appendicitis

This is a section showing numerous ova of schistosoma haematobium with terminal spines. The ova are surrounded by chronic inflammatory cells mainly lymphocytes and eosinophils with fibrosis of the stroma.

\section{Discussion}

Appendicitis is the commonest abdominal surgical emergency in the UK; the lifetime risk of appendicectomy in the US has been reported at $12.0 \%$ for males and $23.1 \%$ for females ${ }^{11}$. It is second most common cause of surgical emergency among pediatric patients in Calabar ${ }^{6}$ The exact aetiology is uncertain, although the most common hypothesis is of obstruction to the appendiceal lumen with secondary infection. The obstruction leads to the accumulation of mucosal secretions and multiplying resident bacteria, thus raising intraluminal and intra-mural pressure. Eventually the pressure causes venous obstruction and thrombosis of the appendicular vasculature, resulting in ischaemia. Bacteria enter the damaged mucosa, and pus forms inside and around the appendix. Ultimately, infarction and perforation occur which can lead to peritonitis, septicaemia and death. Some of the common causes of the obstruction are thought to be a faecolith, lymphoid hyperplasia and adhesions.

Appendicitis is a condition that has been seen to occur in different medical conditions such as pregnancy and has been seen to complicate vetriculoperitoneal shunt surgery for hydrocephalus due to an intracranial space occupying lesion ${ }^{4}$

In a study done among South African pupils and students aged 18-20 years, appendicectomy was very uncommon in rural Negroes $(0.5 \%)$ and periurban Negroes $(0.9 \%)$, slightly more common in urban Negroes $(1.4 \%)$, but very common in Caucasians (16.5\%); prevalences in Coloured and Indian groups were low (1.7 and $2.9 \%$ ). Rural Negroes had a far larger fibre-intake, greater frequency of defecation, and much shorter transittime; yet, in the four ethnic groups in urban areas, despite wide differences in appendicectomy-prevalence, data on these variables were similar ${ }^{12}$

A hospital based study in Kenya show male to female ratio was 1.8:1 which is in contrast to this study and the earlier study done in this centre which all have female preponderance. The median age was 29 (4-71 years). Median pre -hospital delays were one day (normal appendix), one and half days (simple appendicitis), three days (perforated appendix) and six and a half days (appendical abscess). Operative findings were 14\% normal appendix, $42 \%$ simple appendicitis, $22 \%$ perforated, $21 \%$ abscess $^{3}$

In a prospective study done at Ibadan, Nigeria Ninety percent of the patients were between 11-40 years of age. Male patients accounted for $54 \%$ of the cases. Students and civil servants accounted for $68 \%$, while artisans and traders accounted for remaining cases. Low abdominal pain was present in all cases, loss of appetite in $77.7 \%$, and previous history of abdominal pain in $76 \%$. Abdominal tenderness was present in all the patients, rebound tenderness in $77.7 \%$, guarding in $81.5 \%$ and Rovsings sign in $50 \%$. In 12 cases (22\%) the diagnosis was incorrect 8 of which were female patients. In 9.3\% there was perforation. Wound infection and wound dehiscence occurred in $20.4 \%$ and $7.4 \%$ of the cases respectively. It is concluded from this study that acute appendicitis is commonly encountered in private Hospital. Clinical course and postoperative outcome are not different from what obtains in government medical establishments ${ }^{4}$.

The previous study done in Calabar ${ }^{6}$ had Ascaris Lumbricoides as the commonest cause of parasitic infection while this study revealed that Schistomiasis is the commonest parasitic appendical inflammatory 
lesion. Iribhogbe $\mathrm{P}$ et $\mathrm{al}^{13}$ reported a case of diagnostic dilemma in a child with acute appendicitis secondary to

Ascaris lumbricoides in Benin, Nigeria. He emphasized the need for high level of suspicion when dealing with patients of this age group because they may result in several complications.

The ova and cysts of certain parasites were detected and evaluated among patients with appendicitis in south-eastern part of Nigeria by Okolie BI et $\mathrm{al}^{14}$. ova of Enterobius vermicularis, Trichuris trichuria, schistosoma heamatobium, s. manson and Ascaris lumbricoides and cyst of entamoeba histolytica were seen with varied frequencies in the appendix.

\section{Conclusion}

Appendectomy remains the commonest gastrointestinal specimen in Calabar. The procedure is commoner in female however; the incidence of acute appendicitis is commoner in male. Majority of the appendectomy specimens in female are reactive lymphoid hyperplasia while acute suppurative appendicitis with suppuration is commoner in male. This may be due to the fact that female visits the hospital more than the male; they often have a lower pain threshold and are easily convince for any surgical intervention. Chronic appendicitis secondary to parasitic infection mainly schistosomiasis is a common occurrence among the populace.

\section{References}

[1]. Haye's R. Abdominal pain: general imaging strategies. European Radiology, supplement 2004; 14: $123-137$.

[2]. Elechi EN. Acute Appendicitis: A Clinical Pattern In Port Harcourt Nigeria East Afr Med J. 1989; 66(5):328-32

[3]. W S Willmore, AG. Hill, acute appendicitis in a kenyan rural hospital The East African Medical Journal 2001, 78 (7)

[4]. Mwang'ombe NJM, Acute appendicitis following vetriculoperitoneal shunt surgery for hydrocephalus due to an intracranial space occupying lesion AJNS 1999 18,(1)

[5]. Adesunkanmi AR, Acute appendicitis: a prospective study of 54 cases. West Afr J Med. 1993 Oct-Dec;12(4):197-200,

[6]. A E Archibong, I Ekanem, P Jibrin Appendicitis in south eastern Nigerian children. Cent Afr J Med. 1995 Mar ;41 (3):94-7

[7]. Hern andez JA, Swischuk LE, Angel CA et al. imaging of acute appendicitis: US as the primary imaging modality. Pediatric Radiology 2005; 35:392-395

[8]. Rosendahl K, Aukland SM, Fosse K. Imaging strategies in children with suspected appendicitis. European Radiolology, Supplement 2004; 14: 138-145.

[9]. Tauro LF, Premanand TS, Aithala PS, George C, Suresh HB et al Ultrasonography is still a useful diagnostic tool in acute appendicitis, Jounal of Clinical and diagnostic research 2009; 3;5: 1731-1736

[10]. Vegar-Zubovic S, Lincender L, Dizdarevics et al. Ultrasound signs of acute appendicitis in children - clinical application. Radiology and oncology 2005; 39: 15-21+82

[11]. Addiss DG, Shaffer N, Fowler BS, Tauxe RV. The epidemiology of appendicitis and appendicectomy in the United States. Am J Epidem. 1990;132:910-925

[12]. Alexander R. P. Walker, Barbara D. Richardson, B. Faith Walker, Atholie Woolford Postgrad Med J 1973;49:243-249

[13]. Iribhogbe P., Omorogiuwa I. Acute Appendicitis In Young Children-A Diagnostic Challenge JMBR: A Peer-review Journal of Biomedical Sciences 2006; 5 (2)40-43

[14]. B.I. Okolie, I.O. Okonko, A.A. Ogun, A.O. Adedeji, et al Incidence and Detection of Parasite Ova in Appendix from Patients with Appendicitis in South-eastern, Nigeria World Journal of Agricultural Sciences 2008; 4: 795-802 